\title{
Hydrogen Storage in Carbon Nanotubes: Residual Metal Content and Pretreatment Temperature
}

\author{
Angela Lueking and Ralph T. Yang \\ Dept. of Chemical Engineering, University of Michigan, Ann Arbor, MI 48109
}

\begin{abstract}
Hydrogen storage in MWNT was enhanced via the catalytic activity of NiMgO. The magnitude of the hydrogen to metal ratio for the MWNT/NiMgO system, combined with temperature programmed adsorption and desorption studies, showed hydrogen spillover from the catalyst to the carbon surface. Metal doping combined with temperature activation studies showed that both nickel and magnesium are active in the catalytic process. The yield, quality, and carbon-metal contact were shown to affect hydrogen uptake. Higher pretreatment temperatures enhanced uptake, for both low- and high-pressure measurements, due to increased carbon-metal contact and activation of the catalyst. At 69 bar (or 1,000 psia), the hydrogen adsorption and desorption of the $\mathrm{MWNT} / \mathrm{NiMgO}$ system were $3.7 \%$ and $3.6 \%$, respectively.
\end{abstract}

\section{Introduction}

An efficient storage media for hydrogen is desirable for the widespread application of fuel cells and the adoption of hydrogen as an energy source. The U.S. Department of Energy (DOE) has set a target of $6.5 \%$ by weight for hydrogen storage for new adsorbent materials. Although several metal hydrides are capable of meeting this target, the high desorption temperatures and slow desorption rates limit the widespread application of current metal hydrides. Recent advances in carbon nanotechnology have been of interest to chemical engineers, as the development, large-scale production, purification, handling, and uses of carbon nanofibers will require fundamental chemical engineering principles (AIChE Meeting, 2002). Carbon nanofibers, including single-walled carbon nanotubes (SWNTs), multiwall nanotubes (MWNTs), and graphite nanofibers (GNF), have shown promise for applications in hydrogen storage due to the electronic nature resulting from $\mathrm{sp}^{2}$ hybridization, large surface areas, and molecular sized pores.

Hydrogen storage in carbon nanotubes has been reviewed elsewhere (Darkrim et al., 2002; Cheng et al., 2001; Ding et al., 2001) and will be summarized here briefly. Although initial SWNT hydrogen storage reports indicated a high poten-

Correspondence concerning this article should be addressed to R. T. Yang. tial at moderate temperatures and pressures (Dillon et al., 1997), subsequent claims have implied the necessity of high pressure and/or cryogenic conditions (Liu et al., 1999). Recent claims of hydrogen storage in MWNT range from $1.97 \%$ at 40 bar (Lee et al., 2002) to $6.3 \%$ at 148 bar (Hou et al., 2002); both cases show that the structure and purification of the MWNT are key to optimizing hydrogen storage. Recent areas of investigation include the effect of pretreatment to activate the nanotubes (Bockrath et al., 2002), doping of carbon nanofibers with metals (Ritter et al., 2002), and developing prototypes for hydrogen storage systems (Heung et al., 2002; Gadre et al., 2002); ultimately, the implementation of carbon material to mobile fuel cell applications will require understanding the heat effects occurring during charge and discharge (Delahaye et al., 2002; Lamari et al., 2000).

Contamination of carbon materials with metals during preparation (Hirscher et al., 2001) and possible experimental artifacts arising from volumetric adsorption experiments (Tibbetts et al., 2001) have brought into question many hydrogen storage reports. Claims of hydrogen storage in alkali-doped MWNT at moderate temperature and pressure (Chen et al., 1999) were disproven due to water contamination (Yang, 2000; Pinkerton et al., 2000). Other than these experimental artifacts, two other explanations for the lack of reproducibility between laboratories are variations in pre- 
treatment conditions and the effect of residual metal content. Although pretreatment temperatures were shown to be a necessary factor for hydrogen storage in GNF (Park et al., 1999), attempts to replicate these experiments have generally used less extreme pretreatment conditions. High-temperature pretreatments have been shown to remove surface functionalities that may block pores in SWNT (Kuznetsova et al., 2000) or lead to graphitization of MWNT (Li et al., 2001). Secondly, the lack of residual metal characterization, despite inconsistent removal techniques, may explain three common features in hydrogen uptake: slow rates of uptake, partial irreversibility of adsorbed species, and the use of transition metals in synthesis. In fact, incorporation of metals during pretreatment can entirely explain the hydrogen storage under some conditions (Hirscher et al., 2001). Alternatively, residual metal content may enhance the hydrogen uptake of the carbon via hydrogen spillover from the metal to the carbon surface (Lueking and Yang, 2002). Thus, pretreatment conditions and metal content may not only explain the lack of reproducibility but may be used to optimize hydrogen storage in carbon materials. Interestingly, Browning et al. (2002) reported substantial amounts of hydrogen uptake by GNF (containing $\mathrm{Fe} / \mathrm{Ni} / \mathrm{Co}$ catalyst), up to $6.5 \mathrm{wt}$. $\%$ at $12 \mathrm{MPa}$ and ambient temperature. Very slow uptake was also observed; however, hydrogen dissociation on the graphitic edge sites was proposed as the mechanism.

The objectives of this article are to investigate the role of pretreatment and residual metal content on the subsequent hydrogen uptake. The starting point for these studies was a composite MWNT/NiMgO system, which has previously been shown to have desirable hydrogen uptake characteristics (Lueking and Yang, 2002). The addition of a material able to dissociate hydrogen allows hydrogen storage via spillover from the dissociation site to the carbon surface. Both metals and metal oxides are capable of hydrogen dissociation; metal oxides are often already present in nanotubes formed via catalytic synthesis. Through hydrogen spillover, metal oxides form hydrogen bronzes, which is hydrogen intercalated/absorbed into the bulk (for example, Sermon and Bond, 1980). In this study, the residual metal oxide content was characterized and low-pressure studies were used to elucidate and optimize the mechanism of hydrogen spillover and subsequent hydrogen storage on the carbon nanotube surface. The effect of pretreatment temperature and its effect on hydrogen storage was explored in both low- and high-pressure studies.

\section{Methods}

\section{Carbon nanofiber preparation}

All synthesis gases were obtained from cryogenic gases and had the following purities: Matheson grade methane (99.99\%), CP grade ethylene $(99.5 \%)$, pre-purified grade helium $(99.8 \%)$, and ultra-high purity hydrogen (99.999\%).

SWNTs were produced using an iron-molybdenum catalyst supported with a hybrid alumina-silica material, as described by Cassel et al. (1999). GNFs were synthesized by passing a 1:4 ethylene:hydrogen mixture over a 7:3 iron: copper catalyst at $600^{\circ} \mathrm{C}$; these conditions have been shown to produce herringbone GNFs (Krishnakutty et al., 1997). Multiwalled carbon nanotubes were synthesized using a $\mathrm{Ni}_{0.4} \mathrm{Mg}_{0.6} \mathrm{O}$ catalyst at $650^{\circ} \mathrm{C}$, as developed by Chen et al. (1997). All carbon

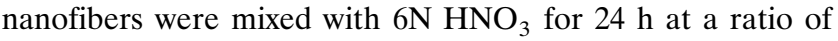
$50 \mathrm{ml}$ acid/g catalyst in an attempt to remove the metals. In addition, the SNWT were treated with $48 \%$ HF (Aldrich) to remove the silica-alumina support.

Variations in externally-produced MWNT yield and quality were induced by varying the methane contact time. High yield SWNT and MWNT were produced in a vertical furnace with the following conditions: $200 \mathrm{~mL} / \mathrm{min}^{\mathrm{CH}_{4}}$ for $3 \mathrm{~h}$ per $\mathrm{g}$ SWNT catalyst; $200 \mathrm{~mL} / \mathrm{min} \mathrm{CH}_{4}$ for $2 \mathrm{~h}$ per g MWNT catalyst. For in situ MWNT production, $10 \mathrm{mg}$ of the catalyst was loaded onto a quartz sample holder and treated on the Shimadzu TGA until the desired MWNT yield was obtained; the metal composition was determined from the normalized weight gain.

GNF were doped with both nickel and a combination of nickel and magnesium as follows: (1) the two materials were dry mixed together and ground with a mortar and pestle; (2) the GNF was mixed with the metal in a $6 \mathrm{~N}^{-\mathrm{HNO}_{3}}$ solution for $24 \mathrm{~h}$, washed, filtered, and dried.

External high-temperature pretreatments were conducted in a quartz reactor with an external furnace. Transfers of the pretreated samples were made in a low-oxygen environment created via repeated purging of a glove bag with ultrahighpurity Argon gas. The final oxygen content in the glove bag was not measured.

\section{Characterization}

The metal composition for the carbon nanofibers was measured using neutron activation analysis (NAA) using P-tube irradiation for magnesium, copper, and aluminum analysis and in-core irradiation for nickel, iron, and molybdenum. Surface area and pore size analysis of the carbon materials were characterized using a Micromeritics ASAP 2000 using nitrogen at $77 \mathrm{~K}$; standard methods were used for BET surface area analysis and BJH desorption and Horvath-Kawazoe pore-size distribution analysis. Prior to measurement, the samples were degassed at $150^{\circ} \mathrm{C}$ in a vacuum.

X-Ray Diffraction measurements were taken with a Rigaku Rotating Anode Diffractometer with $\mathrm{Cu} \mathrm{K} \alpha$ radiation operated at $40 \mathrm{kV}$ and $100 \mathrm{~mA}$. The carbon nanofibers were examined with a Phillips XL30 FEG scanning electron microscope (SEM) and a JEOL 4000 EX high-resolution transmission electron microscope (HRTEM) operated at $400 \mathrm{kV}$ accelerating voltage. Carbon samples were prepared for HRTEM analysis by direct deposition on a lacey carbon on Formvar support grid (Ted Pella, Inc.)

\section{Low-pressure adsorption experiments}

Low-pressure adsorption experiments were performed on a Shimadzu thermogravimetric analyzer (TGA). In each case, $20 \mathrm{mg}$ of carbon nanofibers in a quartz sample holder were pretreated in hydrogen for $1 \mathrm{~h}$ at the desired pretreatment temperature. After pretreatment, the samples were cooled in hydrogen to room temperature at $5^{\circ} \mathrm{C} / \mathrm{min}$, maintained at room temperature for $30 \mathrm{~min}$, and then reheated at a rate of $5^{\circ} \mathrm{C} / \mathrm{min}$. The TGA experiment was a dynamic experiment in that the time was not varied in order for the system to reach equilibrium; this measurement provided an adsorptiondesorption temperature scan. Residual water was removed 
from the analysis gas via an activated 3A zeolite (Grace Davison, Grade 564, 8-12 mesh) column. The total flow rate of analysis gas was $100 \mathrm{~mL} / \mathrm{min}$; a separate set of experiments confirmed that this flow rate was sufficient to eliminate external mass-transfer limitations. All weight gains/losses reported are after correction by a quartz blank calibration; temperature calibrations were made using a standard copper sulfate method.

Adsorption experiments with the metal oxides were conducted in a similar manner as described above with the following variations. $\mathrm{MgO}$ was formed via thermal decomposition of $\mathrm{Mg}(\mathrm{OH})_{2} ; 30 \mathrm{mg}$ of $\mathrm{Mg}(\mathrm{OH})_{2}$ was used in order to obtain a mass of $20 \mathrm{mg}$ after decomposition. A series of experiments were performed sequentially with increasing pretreatment temperature. Heating and cooling rates were $10^{\circ} \mathrm{C} / \mathrm{min}$. Desorption of hydrogen from a packed bed of $\mathrm{Ni}_{0.4} \mathrm{Mg}_{0.6} \mathrm{O}$ was used to confirm that TGA signals were due to hydrogen rather than water contamination in the analysis gas: $1 \mathrm{~g}$ of sorbent was loaded into a quartz reactor, pretreated at $450^{\circ} \mathrm{C}$ in $100 \mathrm{~mL} / \mathrm{min} \mathrm{H}_{2}$, and then exposed to room temperature hydrogen for $8 \mathrm{~h}$. Desorption was commenced with a temperature program of $1^{\circ} \mathrm{C} / \mathrm{min}$, while sampling the exit gas from the bed. The gas samples were analyzed for hydrogen using a Shimadzu GC 8 A with a $2 \mathrm{~m} \times 1 / 8$ in $5 \mathrm{~A}$ zeolite column and $175 \mathrm{~mL} / \mathrm{min}$ Argon as the carrier gas.

\section{High-pressure sorption experiments}

High-pressure hydrogen uptake was assessed using a highpressure volumetric adsorption/desorption system (Figure 1). The unit was specially designed to withstand high-pressure conditions up to 69 bar (1,000 psia), while maintaining leakfree conditions by using VCR face seal compression fittings (H.E. Lennon). The unit consisted of a sample cell module connected to a variable volume sorption reservoir. Bellows valves (4BK, H.E. Lennon) were used to seal the high-pressure portion of the apparatus. The outlet of the sample cell was directed to either a vacuum for pretreatment or a gas regulator to allow controlled flow through the system. Pressure was measured with an ultra high purity pressure transducer (Hi-Tech) connected to a DP41-E panel meter (Omega). The accuracy of the pressure reading was $0.1 \%$ of full scale or 1 psi.

The sample cell consisted of a $\sim 5 \mathrm{~mL}$ stainless steel tube sealed with $0.5 \mu \mathrm{m}$ filtering gasket (H.E. Lennon). Hightemperature valves (Kel-F, H.E. Lennon) at the outlet of the sample cell formed a sample cell module, which could be sealed and detached to facilitate pretreatment. Secondary valves outside the sample cell module were used to maintain "pressure locks" to minimize leakage across valve seats prior to desorption experiments, and additional in-line VCR filters were placed between these double valves to further exclude contamination from the reservoir. Materials for the sample cell module, including valves and fittings, were chosen such that the sample space could be heated to $500^{\circ} \mathrm{C}$ using an external heating source to outgas or otherwise activate the samples. A thermocouple welded into a VCR fitting was used to calibrate an external thermocouple; this welded thermocouple was removed from the system prior to high-pressure readings to minimize leakage.

Initial sample masses for the high-pressure experiments ranged from 100-400 mg. Typically, the same sample was used for a series of experiments in order to elucidate the effect of pretreatment without adding complications due to material inconsistencies. The following variations were used to pretreat the sample: (1) flowing helium through the system at $300^{\circ} \mathrm{C}$; (2) vacuum pretreatment at $500^{\circ} \mathrm{C}$; (3) flowing hydrogen at a specified temperature; (4) external pretreatment with sample transfer in a low-oxygen atmosphere. All flowing gases were passed through a $3 \mathrm{~A}$ zeolite column to remove moisture. After pretreatment and prior to sorption studies,

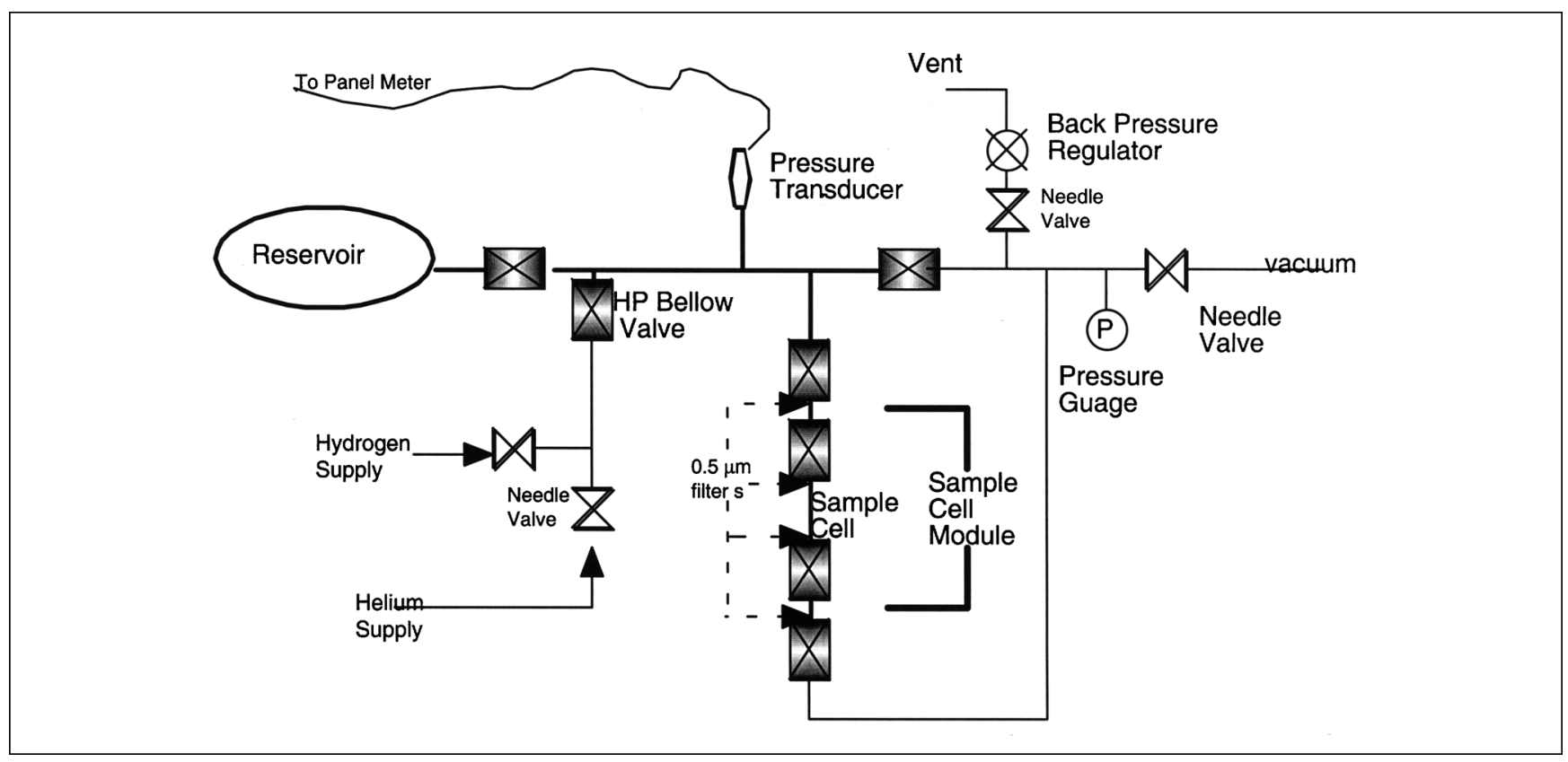

Figure 1. High-pressure adsorption/desorption apparatus. 


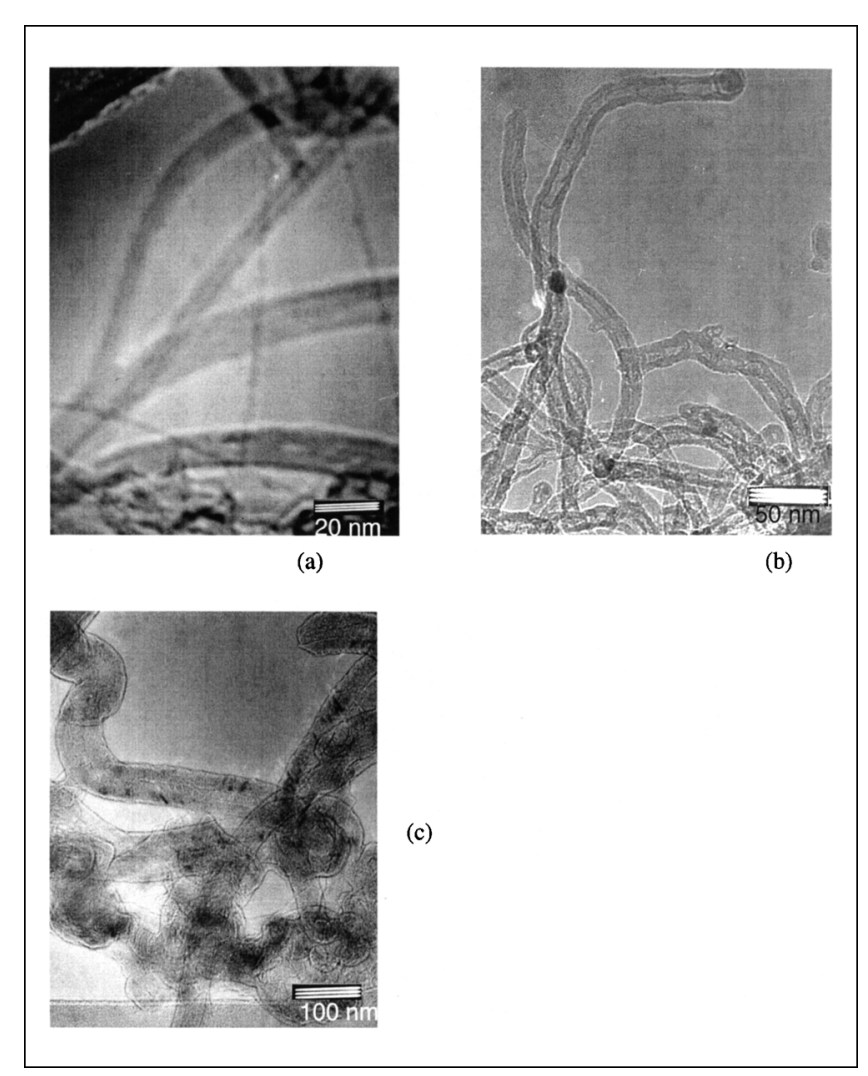

Figure 2. TEM micrographs of carbon nanofibers.

(a) SWNT with diameters of 1.6 and $7.1 \mathrm{~nm}$, indicating a combination of single-wall and double-wall nanotubes; (b) MWNT with an outer diameter of $15 \mathrm{~nm}$; and (d) GNF with a $40 \mathrm{~nm}$ outer diameter.

the integrity of the system was tested via a helium leak test. At the conclusion of each series of desorption measurements, the sample was removed and any changes in the sample mass due to pretreatment were determined through quantitative transfer of the sample.

The volumes of the system were calibrated by attaching a known volume to the sorption reservoir. Hydrogen compressibility factors were confirmed via hydrogen desorption experiments with inactive samples; the best fit to these blank experiments came when the Pitzer correlation was used to correct the compressibility factor at intermediate pressures and the compressibility factors reported by Darkrim et al. (1999) were used to correct pressures above 69 bar.

\section{High-pressure desorption studies}

The system was saturated for greater than $6 \mathrm{~h}$ in flowing hydrogen at the desired adsorption temperature and pressure; the hydrogen was passed through a $3 \mathrm{~A}$ zeolite column to remove any moisture. Adsorption conditions were either constant temperature at 69 bar or a temperature-pressure (T$\mathrm{P})$ cycle. The T-P cycle consisted of a series of step changes where the temperature was cooled as the pressure was increased: $122^{\circ} \mathrm{C}$ and 100 psia; $50^{\circ} \mathrm{C}$ and 500 psia; $25^{\circ} \mathrm{C}$ and 1,000 psia. After adsorption, the sample was cooled to room temperature for desorption measurements and then sealed as the pressure and temperature conditions were recorded. Prior to desorption, the reservoir was depressurized and equilibrated, followed by depressurization of the pressure locks. Immediately after the locks were depressurized, desorption measurements were started by opening the sample cell. Changes in pressure and temperature were recorded as a function of time. Helium calibrations were used to determine the effect of expansion on the pressure readings. The above expansion procedure was repeated until the pressure reached approximately 1 bar. An additional desorption measurement was conducted with sample cell heating. Desorption measurements from each separate pressure expansion were summed up to determine the total desorbable amount.

\section{High-pressure adsorption experiments}

Batch adsorption experiments were conducted immediately after the specified pretreatment. The initial pressure of the sample cell was recorded, and the sample cell module and pressure locks were sealed. The sorption reservoir was pressurized to a predetermined value and allowed to equilibrate. Once the pressure had stabilized, the conditions of the reservoir were recorded, and the valve to the sample cell was opened to allow access to the sample. Pressure and temperature were monitored with time. Blank helium experiments were used to determine the effect of expansion. Subsequent adsorption measurements were conducted at higher pressures for the adsorption isotherm; each incremental adsorption value was added to the previous calculated adsorption to get the total adsorbed hydrogen at a given pressure.

\section{Results and Discussion \\ Characterization of carbon nanofibers}

Nanofiber Synthesis. HRTEM micrographs have been used to confirm the structure of the nanofibers produced by the methods described above. SWNT diameters range from 1.6

Table 1. Characterization of Carbon Nanofibers

\begin{tabular}{|c|c|c|c|c|c|c|c|c|c|c|}
\hline & & HK Pore Vol. & BJH Pore Vol. & BET SA & & & NAA & alysis & & \\
\hline Carbon & ACID & $\left(\mathrm{cm}^{3} / \mathrm{g}\right)$ & $\left(\mathrm{cm}^{3} / \mathrm{g}\right)$ & $\left(\mathrm{m}^{2} / \mathrm{g}\right)$ & $\mathrm{Al} / \mathrm{Si}$ & $\mathrm{Mg}$ & Mo & $\mathrm{Cu}$ & $\mathrm{Ni}$ & $\mathrm{Fe}$ \\
\hline \multirow[t]{2}{*}{ MWNT } & NONE & 0.018 & 0.143 & 47 & $0.09 \%$ & $21.8 \%$ & ND & ND & $32.90 \%$ & $0.04 \%$ \\
\hline & $\mathrm{HNO}_{3}$ & 0.069 & 0.607 & 184 & $0.04 \%$ & $1.05 \%$ & ND & ND & $3.90 \%$ & ND \\
\hline \multirow[t]{3}{*}{ SWNT } & NONE & 0.079 & 0.490 & 207 & $21.60 \%$ & $0.02 \%$ & $0.48 \%$ & ND & $0.08 \%$ & $3.10 \%$ \\
\hline & $\mathrm{HNO}_{3}$ & & & & $21.10 \%$ & ND & $0.31 \%$ & ND & $0.04 \%$ & $3.10 \%$ \\
\hline & $\mathrm{HF}$ & 0.222 & 1.779 & 618 & $0.07 \%$ & $0.10 \%$ & $0.31 \%$ & $0.01 \%$ & $0.14 \%$ & $4.40 \%$ \\
\hline \multirow[t]{2}{*}{ GNF } & NONE & & & 82 & & & & & & \\
\hline & $\mathrm{HNO}_{3}$ & 0.196 & 0.188 & 45 & $0.01 \%$ & ND & ND & $0.01 \%$ & ND & $0.25 \%$ \\
\hline
\end{tabular}


$\mathrm{nm}$ to $7.1 \mathrm{~nm}$; the sample shows single-wall nanotubes, as well as bundles of SWNTs, double- and multiwall nanotubes (Figure 2a). The MWNT have a fairly consistent diameter of $15 \mathrm{~nm}$ (Figure 2b). The resulting GNF had two distinct sizes, ranging from $40-150 \mathrm{~nm}$, of which a representative $40 \mathrm{~nm}$ sample is shown (Figure 2c).

Surface Area and Pore-Size Distribution. The physical characteristics of the carbon nanofibers, including surface area and pore-size distribution, are listed in Table 1. The SWNTHF sample had a surface area of $618 \mathrm{~m}^{2} / \mathrm{g}$, the largest surface area of all the nanofibers. The surface area of the untreated SWNT was $207 \mathrm{~m}^{2} / \mathrm{g}$, indicating that removal of the catalyst increases the surface area significantly by removing the metal particles and opening the tubes. The $6 \mathrm{~N}$ HNO3 treated MWNT sample (MW-HNO3) had a surface area of $184 \mathrm{~m}^{2} / \mathrm{g}$, which is three-fold less than the SW-HF sample. The GNF had the lowest surface area of the three samples. Pore volumes calculated both by BJH desorption and Horvath-Kawazoe methods are largest for the SW-HF sample. These results indicate that the SW-HF sample has the most favorable physical adsorption characteristics.

Residual Metal Content. The metal analysis of the carbon nanofibers, before any subsequent thermal pretreatment, shows that a particular acid treatment (such as, 6N HNO3) does not result in an equal residual metal content for all carbon nanofibers (Table 1). The extent of removal depends upon the initial synthesis catalyst, its initial concentration determined by the carbon nanofiber yield, possible encapsulation of the metal during synthesis, and its relative solubility in the given acid. The MWNT-HNO3 had $\sim 5 \%$ of the synthesis catalyst ( $\mathrm{Ni}$ and $\mathrm{Mg}$ ), whereas SWNT treated in $6 \mathrm{~N}$ HNO3 had a residual $24.6 \%$ metal content of which $3.5 \%$ was the transition metals used in synthesis (Fe and Mo). Treatment of the SWNT in HF effectively reduced the silica-alumina content to $0.07 \%$, but the transition metal content was still

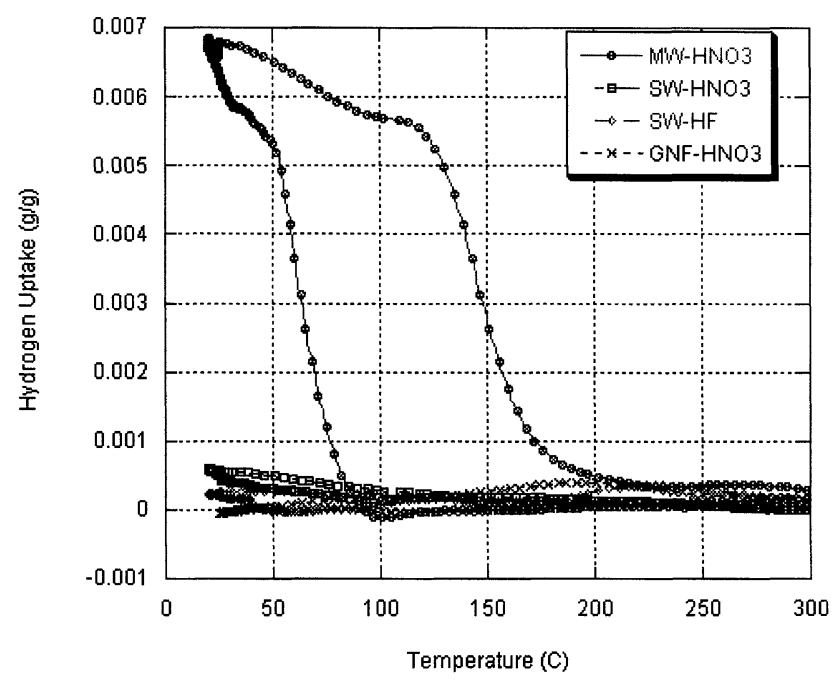

Figure 3. Comparison of hydrogen uptake for different carbon nanofibers.

The highest uptake, $0.68 \%$, was for the MW-HNO3 sample that had a large residual $\mathrm{Ni}$ and $\mathrm{Mg}$ content. The uptake of the SW-HF sample was less than $0.06 \%$ despite its favorable surface area and pore-size distribution.
4.7\%. The metal content of the GNF was less than $1 \%$ after acid treatment. Thus, residual metal content may be highly variable even when identical acid treatments are used.

\section{Low-pressure hydrogen uptake studies}

The hydrogen uptake at atmospheric pressure shows that the MWNT treated with $6 \mathrm{~N}$ HNO3 has the largest hydrogen uptake at $0.68 \%$ (Figure 3). SW samples (both HF- and HNO3-treated) and the GNF (HNO3-treated) all had uptakes less than $0.06 \%$. Repeated runs of the MW-HNO3 showed that the hydrogen uptake was reproducible and reversible for a given sample at atmospheric pressure. Several grab samples of the MW-HNO3 were run, and the uptake was always in the range of $0.4-0.7 \%$.

Role of Residual Metals in Hydrogen Uptake. Comparisons of the physical characteristics of the carbon nanofibers to their corresponding hydrogen uptake show that surface area and pore size distribution are insufficient predictors of hydrogen uptake. However, comparison of the hydrogen uptake to residual metal content suggests that this may contribute to the hydrogen uptake of the MW-HNO3 sample. Although the metal content of the SW-HF was comparable to that of the MWNT-HNO3, the Fe-Mo catalyst becomes inactive to hydrogen uptake after methane exposure due to encapsulation of the metal (Lueking and Yang, 2003). The effect of residual metals on hydrogen uptake has been largely unstudied and uncharacterized in previous hydrogen storage studies; this may indeed explain the irreproducibility between different laboratories.

Lueking and Yang (2002) previously showed that the residual nickel and magnesium found in the MWNT-HNO3 system is necessary for the hydrogen uptake. In these studies, hydrogen uptake of the combined MWNT/NiMgO system was virtually eliminated with additional catalyst removal. In addition, the initial $\mathrm{Ni}_{0.4} \mathrm{Mg}_{0.6} \mathrm{O}$ used in synthesis had qualitatively similar behavior to the composite MW-HNO3 system. Their results clearly showed that $\mathrm{Ni}_{0.4} \mathrm{Mg}_{0.6} \mathrm{O}$ was a neces-

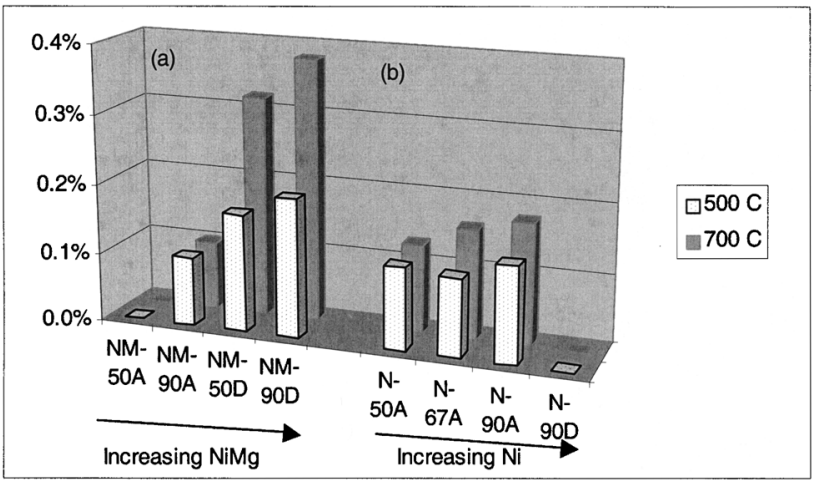

Figure 4. Doping of GNF with both (a) NiMgO, and (b) $\mathrm{Ni}$ induces hydrogen uptake in the previously inactive GNF samples.

The hydrogen uptake increases for increasing $\mathrm{Ni}-\mathrm{Mg}$ content, whereas the effect of Ni-only concentration is less evident. Increasing the pretreatment temperature in the case of the dry-mixed GNF and $\mathrm{NiMgO}$ samples increases the subsequent hydrogen uptake. The concentration of the dopants are indicated with A denoting acid doping and D denoting dry mixing. 


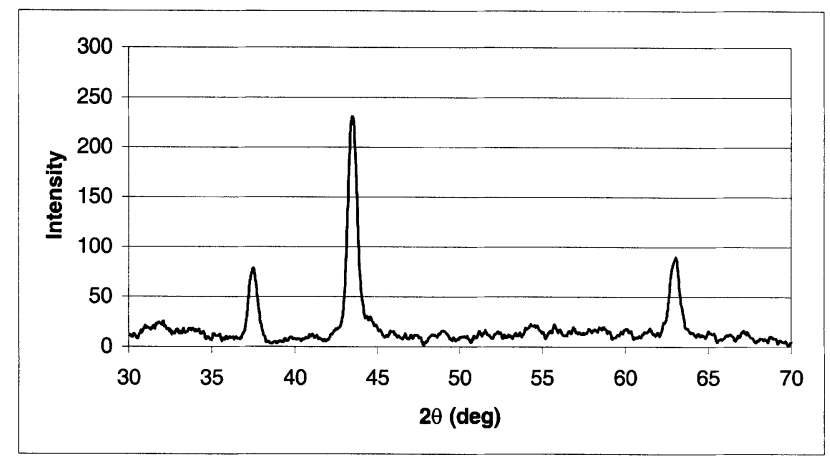

Figure 5. An example XRD profile for the NiMgO sample after prior exposure to hydrogen at $700^{\circ} \mathrm{C}$

The peaks shown are typical for $\mathrm{NiMgO}$ and show no evidence of reduction, thus ruling out the possible formation of metal hydrides.

sary component of the hydrogen uptake in the combined MWNT/NiMgO system, however normalization of hydrogen uptake on a per metal basis showed that the carbon was also participating in the hydrogen adsorption. For the results presented here, normalization of the $0.68 \%$ uptake for the MWHNO3 on a per metal ion basis results in a $\mathrm{H}$ :Me ratio of 1.4 , whereas calculation of the $\mathrm{H}$ :Me ratio of the $\mathrm{Ni}_{0.4} \mathrm{Mg}_{0.6} \mathrm{O}$ sample reported by Lueking and Yang shows that the $\mathrm{H}: \mathrm{Me}$ ratio in the metal oxide sample does not exceed 0.3.

To further delineate the role of nickel and magnesium in hydrogen uptake, a GNF sample was doped both by dry-mixing and using acidic (6N HNO3) conditions. As GNF was synthesized with an iron-copper catalyst, it had no prior exposure to nickel or magnesium. Treatment of the GNF in $6 \mathrm{~N}$ HNO3 will give the catalyst a nucleation site (Yu et al., 1998) on the carbon surface, and is similar to the conditions under which $\mathrm{NiMgO}$ was removed and deposited upon the MWNT. As the Ni-Mg content in the GNF increased, the hydrogen uptake increased accordingly, up to a maximum of $0.38 \%$; this is an eight-fold increase over the undoped GNF sample (Figure 4). Although dry-mixing of the GNF with nickel powder did not enhance hydrogen uptake, enhancement did occur when the materials were doped under acidic conditions. In the absence of $\mathrm{Mg}$, nickel doubled the hydrogen uptake of the GNF to $0.11-0.18 \%$; however, the nickel content of the material had a less pronounced effect on the hydrogen uptake compared to the nickel-magnesium. Samples with $\mathrm{Mg}$ contents exceeding 100 PPM (NM-50D and NM-90D) had enhanced hydrogen uptake when pretreated at $700^{\circ} \mathrm{C}$, as discussed below.

Table 2. Hydrogen Uptake for Catalytic Materials as a Function of Pretreatment Temperature

\begin{tabular}{ccc}
\hline \multirow{2}{*}{$\begin{array}{c}\text { Pretreatment } \\
\text { Temp. }\left({ }^{\circ} \mathrm{C}\right)\end{array}$} & \multicolumn{2}{c}{ Hydrogen Uptake $(\mathrm{g} / \mathrm{g})$} \\
\cline { 2 - 3 } & $\mathrm{MgO}$ & $\mathrm{NiMgO}$ \\
\hline 400 & $\mathrm{NA}$ & $0.83 \%$ \\
700 & $0.30 \%$ & $0.76 \%$ \\
825 & $0.65 \%$ & $0.75 \%$ \\
950 & $0.67 \%$ & $0.67 \%$ \\
\hline
\end{tabular}

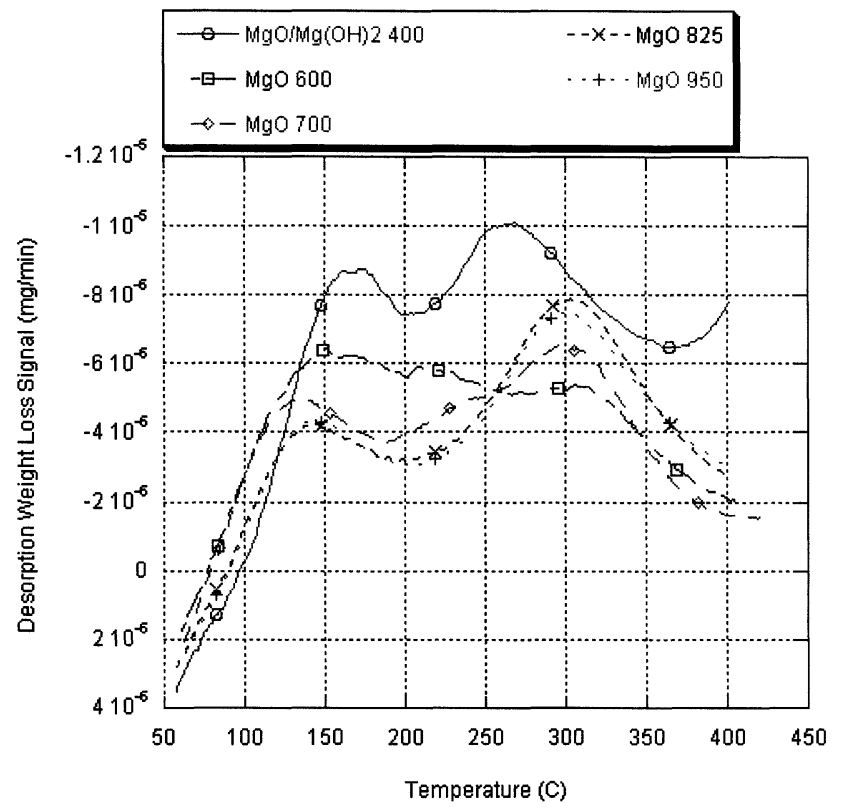

Figure 6. TGA desorption signal for hydrogen from $\mathrm{MgO}$ after activation in high-temperature hydrogen.

The multipeak desorption signal is similar to that found by Ito et al. $(1981,1983)$.

Activation and Characterization of the Catalyst. Understanding the catalytic activity of the metal oxides is key to understanding and optimizing the catalytic effect in the composite MWNT/NiMgO system, as well as extending the measurements to high-pressure conditions. Due to the hydrophilic nature of the materials and previous reports of water contamination (Yang, 2000; Pinkerton et al., 2000), the possibility of water adsorption was studied via a packed-bed study with GC analysis. Analysis of the desorbed products from a $\mathrm{Ni}_{0.4} \mathrm{Mg}_{0.6} \mathrm{O}$ packed bed confirmed that hydrogen was evolving from the metal oxide activated at $450^{\circ} \mathrm{C}$, whereas no hydrogen desorbed from the inactivated $\mathrm{Ni}_{0.4} \mathrm{Mg}_{0.6} \mathrm{O}$.

$\mathrm{Ni}_{\mathrm{y}} \mathrm{Mg}_{1-\mathrm{y}} \mathrm{O}$ is a true solid solution, as $\mathrm{Ni}$ and $\mathrm{Mg}$ have the same valency and approximately the same ionic size (Kiselev and Krylov, 1989). Although nickel-magnesium alloys are commonly used to form metal hydrides, XRD studies rule out hydride formation as the bulk of the nickel and magnesium remains in oxidized form, even after hydrogen exposure (Figure 5). Similar XRD results were found when the MWNT were present. The $\mathrm{MgO}$ keeps the bulk Ni in oxidized form, whereas surface Ni may become reduced (Chen et al., 1997). The distribution of Ni between the surface and the bulk depends upon the temperature of pretreatment; at mid-range temperatures $\left(400-600^{\circ} \mathrm{C}\right)$, the nickel tends to segregate to the surface upon cooling, whereas, at higher temperatures, there is an equal distribution of nickel between the surface and the bulk (Kiselev and Krylov, 1989). The surface nickel likely acts as catalytic sites for hydrogen dissociation.

$\mathrm{MgO}$ is able to store hydrogen (Table 2, Figure 6, consistent with literature reports (Coluccia et al., 1982). The multipeak desorption profile of $\mathrm{MgO}$ (Figure 6) is similar to that reported previously (Ito et al., 1981, 1983). The optimum hydrogen uptake for $\mathrm{MgO}$ occurred after a pretreatment 
temperature of $825^{\circ} \mathrm{C}$, consistent with previous reports (Ito et al., 1981). Heat activation of $\mathrm{MgO}$ forms paramagnetic centers, which are active in hydrogen dissociation (Paganini et al., 1999). Although heat activation of $\mathrm{MgO}$ in hydrogen has not been studied, exposure of $\mathrm{MgO}$ to hydrogen atoms may propagate the paramagnetic centers through the bulk as the surface becomes progressively more hydroxylated (Smith and Tench, 1968; Tench and Lawson, 1970). Although the samples were treated in hydrogen gas rather than hydrogen atoms, it is possible that hydrogen was able to dissociate at the high pretreatment temperatures. This may explain why the $0.67 \%$ adsorption reported here is significantly higher than samples heat treated in vacuo (Ito et al., 1981). The magnitude of the uptake reported here indicates that hydrogen likely becomes dissolved/intercalated within the bulk oxide, as will be discussed below.

$\mathrm{Ni}_{0.4} \mathrm{Mg}_{0.6} \mathrm{O}$ required lower pretreatment temperatures to activate the catalyst, as was expected as $\mathrm{Ni}$ is used to enhance the catalytic activity of $\mathrm{MgO}$ (Kiselev and Krylov, 1989). The maximum uptake of hydrogen by $\mathrm{Ni}_{0.4} \mathrm{Mg}_{0.6} \mathrm{O}$ was $0.83 \%$ and occurred at the lowest pretreatment temperature of $400^{\circ} \mathrm{C}$. As the pretreatment temperature was increased, the

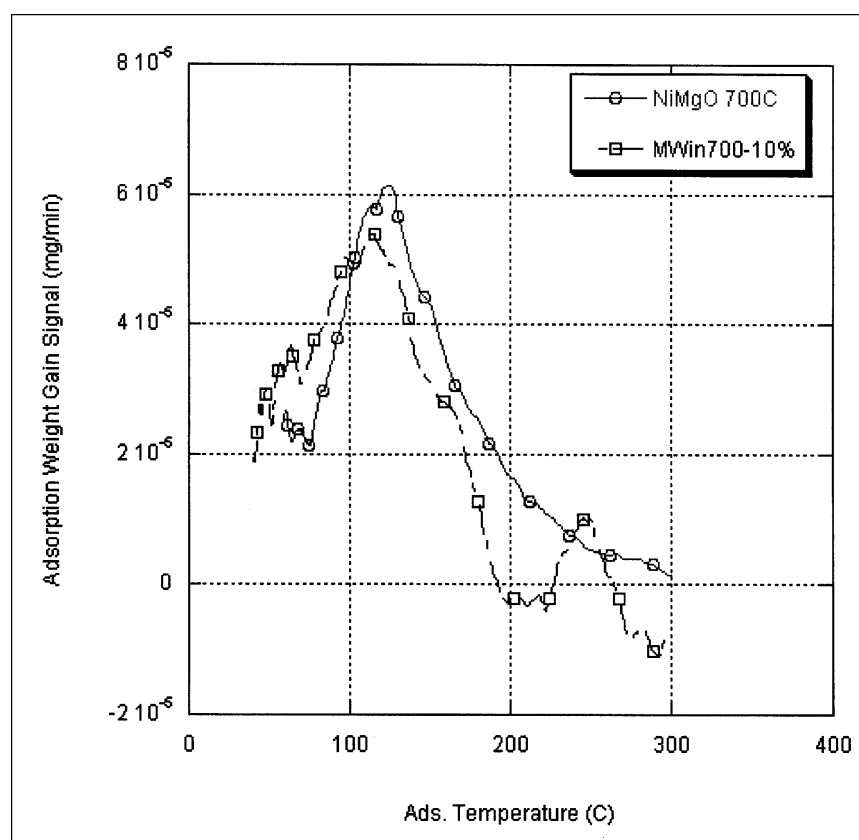

(a)

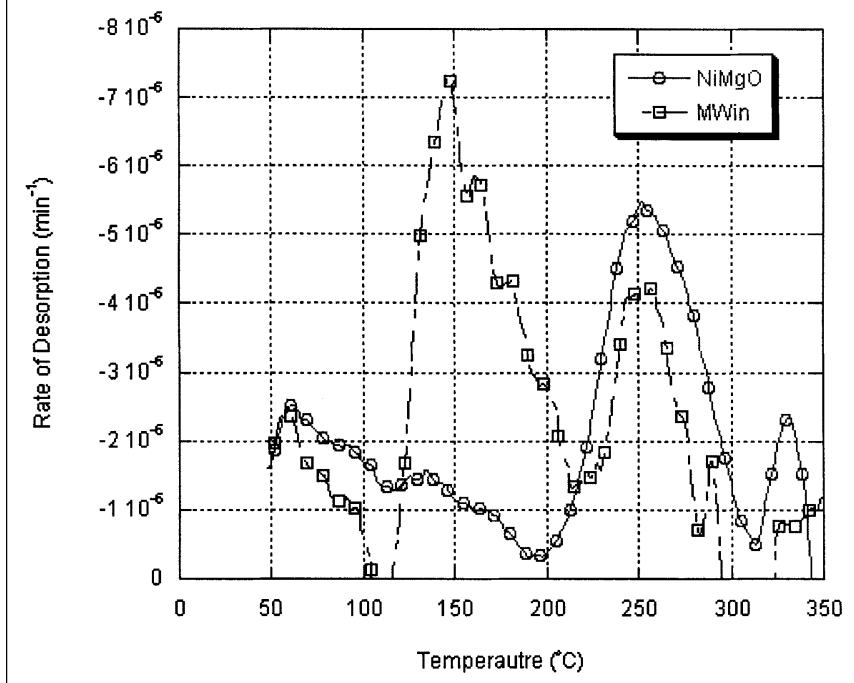

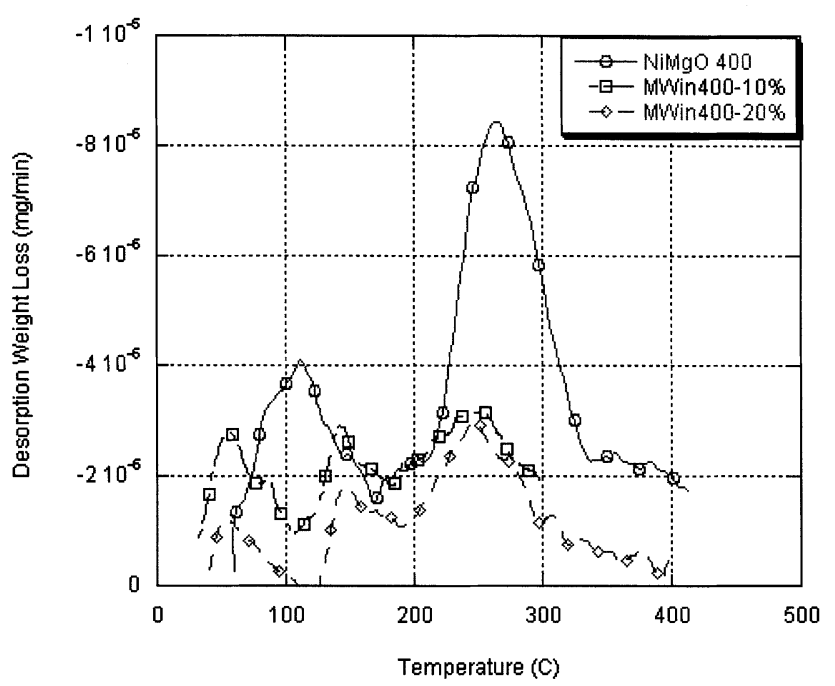

(c)

Figure 7. temperature profile for (a) adsorption and (b) desorption of hydrogen onto both NiMNgO and MWNT formed in situ (MW-in) at $700^{\circ} \mathrm{C}$; (c) in situ MWNT formed at lower temperatures reduce hydrogen uptake and do not have a strong low temperature desorption peak.

The adsorption temperature for adsorption is the same for both samples (a) and (b), whereas desorption from the MW-in occurs at a lower temperature. 
hydrogen uptake decreased, likely due to surface annealing or the enhanced surface nickel concentration at pretreatment temperatures between $400-600^{\circ} \mathrm{C}$ (Kiselev and Krylov, 1989). Although the uptakes for $\mathrm{Ni}_{0.4} \mathrm{Mg}_{0.6} \mathrm{O}$ are comparable to that reported for the $\mathrm{MW} / \mathrm{NiMgO}$ composite system, it is important to remember that when normalized on a per catalyst basis, the H:Me ratio is substantially higher for the composite system (1.4 vs. 0.3). Hydrogen spillover is expected to increase with the square root of pressure. To extend these results to high pressure, a lower pretreatment temperature of $400^{\circ} \mathrm{C}$ is desirable to activate the $\mathrm{Ni}_{0.4} \mathrm{Mg}_{0.6} \mathrm{O}$; however, this may not be the optimal temperature to induce the proper carbon-metal interactions as discussed below.

The magnitude of the hydrogen uptake for both the $\mathrm{MgO}$ and the $\mathrm{Ni}_{0.4} \mathrm{Mg}_{0.6} \mathrm{O}$ suggest that the hydrogen is not limited to the surface and diffuses into the bulk. Hydrogen intercalation in metal oxides has been described previously and results in the formation of hydrogen bronzes. One mechanism for hydrogen bronze formation is through hydrogen spillover from a surface metal to the oxide (Sermon and Bond, 1980); although the surface metal may be unnecessary if atomic hydrogen is present, as was shown in the case of $\mathrm{MoO}_{3}$ (Erre et al., 1983). A well-characterized example of a hydrogen bronze is $\mathrm{H}_{2 \mathrm{x}} \mathrm{V}_{2} \mathrm{O}_{5}$, which is formed at about $65^{\circ} \mathrm{C}$ and decomposes into a suboxide above $200^{\circ} \mathrm{C}$; in this case the final hydrogen content $\mathrm{x}$ is between 1.5 and 1.9 (Tinet et al., 1986). Typically, the hydrogen content of hydrogen bronzes is dependent upon pressure and is often quantifiable at ambient pressure (Fripiat and Lin, 1992). The general structural features of the metal oxide lattice are retained, but in some cases the hydrogen bronze may have a different symmetry than the starting material (Tinet et al., 1986). As oxygen is not removed, the formation of hydrogen bronzes is not a "true" reduction although the hydrogen may donate electrons to the lattice (Tinet et al., 1986; Pichat et al., 1988). Hydrogen bronzes have interesting catalytic properties; for example, $\mathrm{H}_{\mathrm{x}} \mathrm{MoO}_{3}$ is an active hydrogenation catalyst (Marcq et al., 1982). The ability of $\mathrm{NiMgO}$ to form hydrogen bronzes may very well be related to its activity in the formation of carbon nanotubes-upon methane dissociation, the oxide catalyst acts as a reservoir for the displaced hydrogen. To our knowledge, the formation of $\mathrm{a}_{\mathrm{x}} \mathrm{Ni}_{\mathrm{y}} \mathrm{Mg}_{1-\mathrm{y}} \mathrm{O}$ has not previously been reported, but its formation via hydrogen spillover is certainly consistent with literature reports and our evidence of hydrogen spillover. Comparing the hydrogen content and active temperature range for $\mathrm{H}_{2 \mathrm{x}} \mathrm{V}_{2} \mathrm{O}_{5}$ to that reported here further supports the formation of a hydrogen bronze of the type: $\mathrm{H}_{\mathrm{x}} \mathrm{Ni}_{0.4} \mathrm{Mg}_{0.6} \mathrm{O}$. Future work will include characterization of this material.

Mechanism for Hydrogen Spillover. The H:Me ratio of the MWNT/NiMgO is 1.4, compared to a $\mathrm{H}: \mathrm{Me}$ ratio of 0.3 for the $\mathrm{Ni}_{0.4} \mathrm{Mg}_{0.6} \mathrm{O}$. Lueking and Yang (2002) showed the ability of MWNT to uptake hydrogen was substantially reduced with further removal of the catalyst. These two conditions show that hydrogen adsorbs on the surface of the metal oxide and then spills over to the carbon support. The previously reported desorption activation energy of $96.9 \mathrm{~kJ} / \mathrm{mol}$ suggests that the adsorption and desorption of hydrogen is a chemisorption process (Lueking and Yang, 2002). The formation of MWNT adsorption sites resulting from in situ MWNT synthesis (MW-in) helps elucidate this process. The majority of the hydrogen adsorbs at $120^{\circ} \mathrm{C}$ for both $\mathrm{MW}$-in and $\mathrm{Ni}_{0.4} \mathrm{Mg}_{0.6} \mathrm{O}$, although a lesser amount adsorbs at $250^{\circ} \mathrm{C}$ for MW-in (Figure 7a). The desorption profile for $\mathrm{MW}$-in shows a stronger desorption peak at $130^{\circ} \mathrm{C}$ than $\mathrm{Ni}_{0.4} \mathrm{Mg}_{0.6} \mathrm{O}$, which has a dominant desorption peak at $240^{\circ} \mathrm{C}$ (Figure $7 \mathrm{~b}$ ). Comparing $\mathrm{NiMgO}$ to $\mathrm{MW}$-in, the adsorption profiles are essentially the same, whereas MW-in has a much stronger lowtemperature desorption peak. This supports adsorption via hydrogen spillover from the metal to the carbon and subsequent desorption directly from the carbon. Ab initio molecular orbital studies show adsorption of hydrogen atoms is exothermic and stable on the graphite plane (Yang and Yang, 2002). Our proposed mechanism for the process is as follows: hydrogen dissociatively adsorbs onto active surface sites on the $\mathrm{Ni}_{0.4} \mathrm{Mg}_{0.6} \mathrm{O}$ and then migrates both to the interior of the catalyst and onto the graphitic plane of the MWNT; upon heating, the hydrogen recombines and desorbs directly from the lower energy sites on the carbon surface.

MWNT Quality, Metal-Carbon Contact, and Hydrogen Spillover. The quality of the MWNT formed during synthesis is a factor in subsequent adsorption and desorption. For example, MWNT synthesis at temperatures of $400^{\circ} \mathrm{C}$ and $450^{\circ} \mathrm{C}$ do not enhance adsorption and result in blocking of the $\mathrm{NiMgO}$ sites (Figure 7c). As the yield of MWNT at this temperature is low (Chen et al., 1997), the carbon formed is likely amorphous and causes coke formation which blocks the catalytic sites.

For hydrogen spillover to occur, it is well established that appropriate contact between the metal and carbon must be present (Boudart et al., 1970). As shown by Lueking and Yang (2002), dry mixing of the catalyst and the MWNT did not enhance hydrogen storage on a per catalyst basis, whereas in situ formation of the nanotubes in the TGA enhanced the hydrogen storage by $40 \%$. The results presented here for in situ formation of MWNT show that there is an optimal yield for hydrogen spillover, in terms of both normalized and absolute weight gain (Table 3). Low to intermediate synthesis times increase the hydrogen uptake of the catalyst by $\sim 20 \%$, whereas longer reaction times do not enhance hydrogen uptake.

For externally produced MWNT, a similar relationship between MWNT yield and uptake is observed. By varying the methane exposure time while keeping other factors constant, higher yields are detrimental to subsequent hydrogen uptake (Figure 8). Despite identical acid treatments, longer synthesis times lower hydrogen uptake by $34-75 \%$. The effect of synthesis time needs to be explored by further analysis of the MWNT characteristics, but increases in methane exposure may decrease hydrogen uptake due to any of the following factors: (1) encapsulation of the catalyst (similar to that found

Table 3. Various MWNT Yield for Optimization of Hydrogen Uptake

\begin{tabular}{ccccc}
\hline $\begin{array}{c}\text { Reaction } \\
\text { Time } \\
(\min )\end{array}$ & $\begin{array}{c}\text { NT } \\
\text { Comp. }\end{array}$ & $\begin{array}{c}\text { Overall } \mathrm{H}_{2} \\
\text { Uptake }\end{array}$ & $\begin{array}{c}\text { T Des., } \\
\text { Max }\left(^{\circ}\right)\end{array}$ & $\begin{array}{c}\mathrm{H}_{2} \text { Mass }(\mathrm{mg}) \\
\text { Desorb at } \\
T<200^{\circ} \mathrm{C}\end{array}$ \\
\hline 0 & 0 & $0.81 \%$ & 245 & 0.028 \\
2 & $5 \%$ & $0.90 \%$ & 134,240 & 0.063 \\
6 & $6 \%$ & $0.94 \%$ & 177,265 & 0.069 \\
30 & $17 \%$ & $0.80 \%$ & 141,240 & 0.038 \\
\hline
\end{tabular}




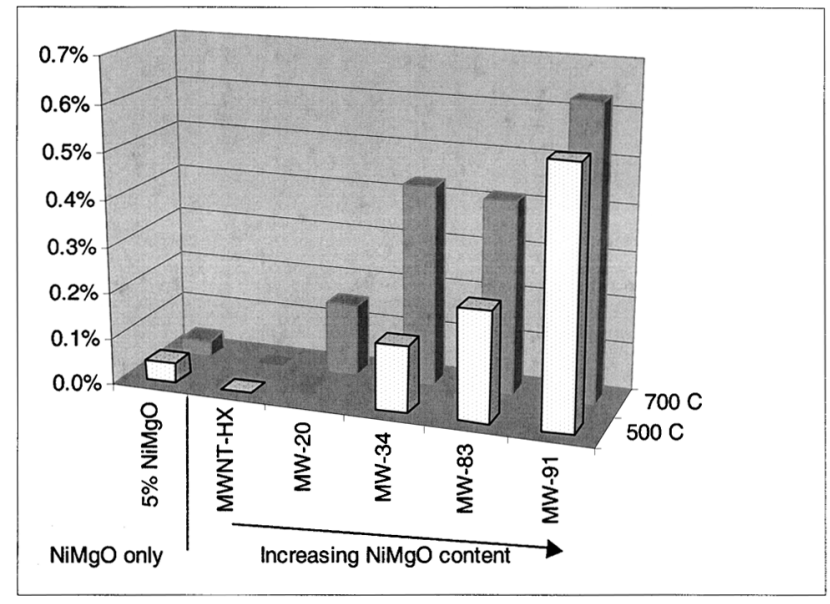

Figure 8. Hydrogen storage in the MWNT increased for low-yield samples and was enhanced with higher pretreatment temperatures.

The MW samples have increasing $\mathrm{NiMgO}$ content due to increased reaction times. The numbers in the sample names indicate the $\mathrm{NiMgO}$ weight percentage prior to acid treatment.

in Figure 7c); (2) changes in the quality of the MWNT with longer synthesis times, and/or (3) less effective metal-carbon contact with longer synthesis times.
Pretreatment Temperature, Gasification, and Activation. There is a clear dependence on pretreatment temperature for both the Ni-Mg-doped GNF (Figure 4) and for the MWNT/NiMgO system (Figure 8), which is true for the $\mathrm{MgO}$ catalyst, but not for $\mathrm{Ni}_{0.4} \mathrm{Mg}_{0.6} \mathrm{O}$ (Table 2). For the MWNT, increasing the pretreatment temperature from $500^{\circ} \mathrm{C}$ to $700^{\circ} \mathrm{C}$ doubles the hydrogen uptake for high-yield nanotubes. In the case of the Ni-Mg doped GNF, increasing the pretreatment temperature from $500^{\circ} \mathrm{C}$ to $700^{\circ} \mathrm{C}$ increases the hydrogen uptake by up to $90 \%$. This effect is not observed for samples doped with $\mathrm{Ni}$ only. Elemental analysis shows that the samples with that show enhanced uptake after $700^{\circ} \mathrm{C}$ pretreatment correspond to the samples with $\mathrm{Mg}$ contents greater than 100 PPM. This suggests that the pretreatment effect is due in part to the activation of paramagnetic centers in the $\mathrm{MgO}$.

Pretreatment at $700^{\circ} \mathrm{C}$ also results in increased gasification of the carbon samples: the highest gasification for the GNF results in $\sim 20 \%$ mass loss, whereas the mass loss for the MWNT/NiMgO system is as high as $85 \%$. This gasification increases the relative metal content of the samples: for MWNT/NiMgO, the residual metal content is increased from $5 \%$ to $\sim 20 \%$. Despite the increased metal content, several factors show that the MWNT are still active and have already been discussed, including: temperature-programmed adsorption and desorption studies and the H:Me ratio. SEM micrographs of samples after high-temperature hydrogen pretreat-

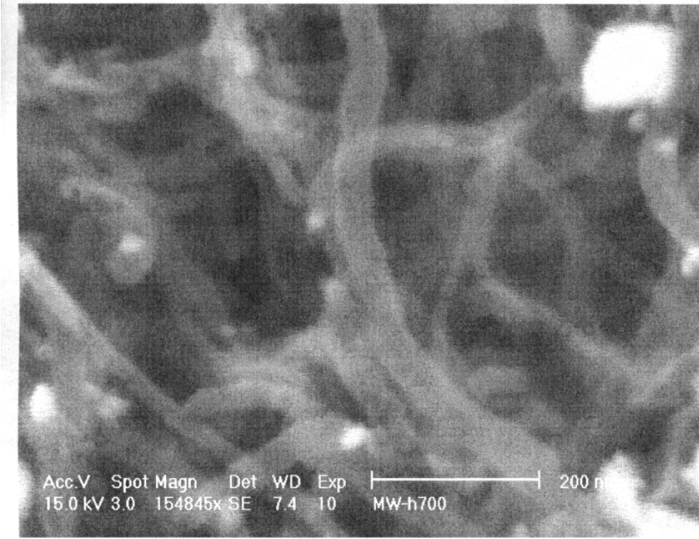

(a)

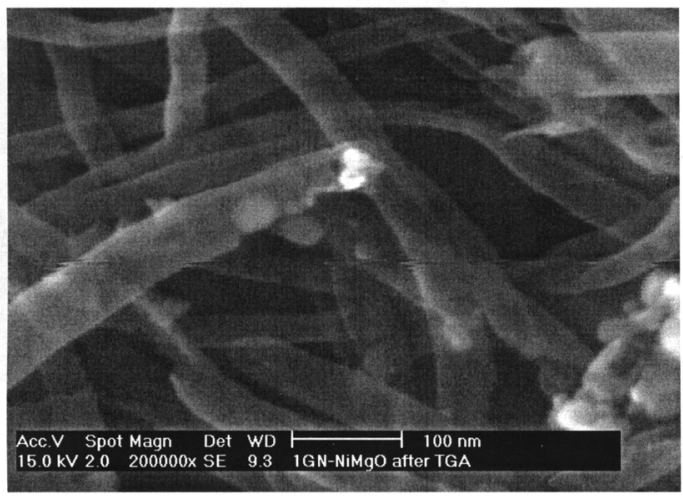

(b)

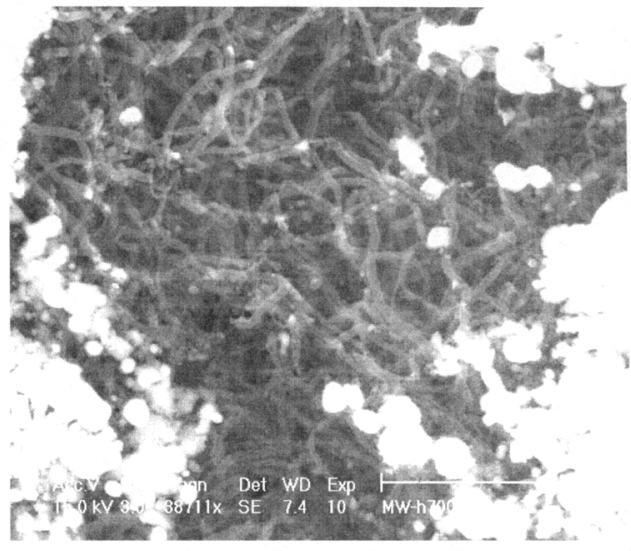

(d)

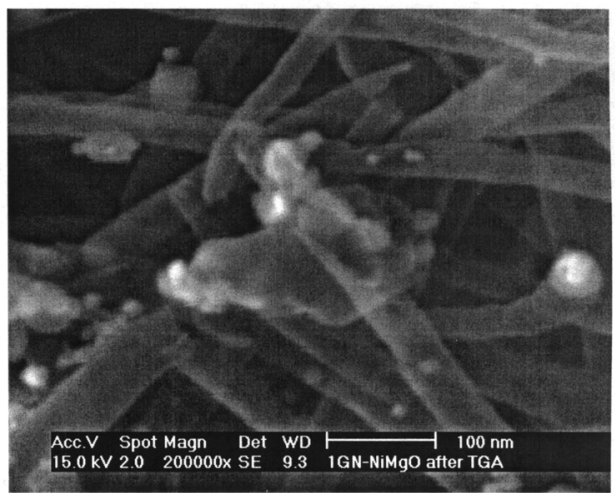

Figure 9. Effect of $700^{\circ} \mathrm{C}$ treatment on carbon structure.

(a) The tubular structures of the MWNT remain intact after high-temperature pretreatment, but (b) gasification of the carbon has led to regions with high metal content. (c) Although evidence exists for side tunneling in the GNF, (d) the majority of gasification is a result of end tunneling and complete gasification of the graphitic structure. 
ment show that the tubular structure of the MWNT remains intact, while gasification has led to regions with high metal content (Figures 9a and 9b).

The increases in normalized hydrogen uptake (Figures 4 and 7) are, of course, increased when gasification results in decreased sorbent mass. However, comparison of samples treated at $700^{\circ} \mathrm{C}$ to those treated at $500^{\circ} \mathrm{C}$ shows that the absolute hydrogen weight gain increases as well, suggesting activation of the samples at higher pretreatment temperatures. Previous studies have explained high-temperature activation to be due to removal of chemisorbed species (Park et al., 1999), destruction of surface functionalities that may block pores (Kuznetsova et al., 2000), or graphitization of the nantoubes ( $\mathrm{Li}$ et al., 2001). Extension of these explanations to the results presented here is partially limited by the differences in pretreatment conditions; the previous studies were conducted in inert atmospheres and did not consider the effect of residual catalysts in the activation process. The pretreatment conditions in this study were in a reducing environment with a high level of residual catalyst; these conditions are in fact conditions that favor the reverse of the MWNT formation reaction. The presence of a metal contaminant, its corresponding high surface area after acid treatment, and the pretreatment temperature of $700^{\circ} \mathrm{C}$ are conditions that may allow tunneling and/or deep layer channeling of nickel into the graphitic structure; for example, nickel monolayer channeling commences at approximately $700^{\circ} \mathrm{C}$ and the rate increases with increasing nickel surface area (Goethel and Yang, 1987). This is a useful comparison despite the fact that it is not pure nickel metal remaining in the carbon samples, as tunneling and/or channeling could activate the sample by creating terminal carbons. In the case of the dopedGNF, some deep layer channeling of the metal into the side of the GNF is observed (Figure 9c); however, the observation of this effect was rare for GNF (Figure 9d) and no such tunneling was observed for the smaller MWNT. Thus, gasification likely occurs from the end of the tubes, limiting the creation of additional terminal carbons via tunneling.
In graphite gasification, the following mechanism is generally accepted: dissolution of carbon into the metal at the leading edge of the metal particle; diffusion of carbon in the metal to the top and rear surfaces of the particle where carbon is converted into gaseous products (Goethel and Yang, 1987). This mechanism suggests that the observed activation is due to increased contact between the metal and carbon, which in turn enhances hydrogen spillover. Future work will elucidate the mechanism of activation; the ability of the $\mathrm{NiMgO}$ to activate the GNF suggests that graphitic powder may also be activated by this pretreatment process.

\section{High-pressure studies}

Minimization of Experimental Artifacts. Due to the required sensitivity of the measurement, high-pressure hydrogen adsorption studies are especially prone to error and experimental artifacts. The molecular size of hydrogen makes the adsorption system especially prone to leakage-both in the fittings and across the valves. Additional artifacts arise due to small variations in calculation of the compressibility factor, changes in the internal temperature due to expansion effects, and the effect of room temperature fluctuations on high-pressure measurements (see, for example, the discussion by Tibbetts et al. (2001)).

The high-pressure experiments in this work were designed to minimize these possible experimental artifacts. First, leakage was minimized using VCR face seal compression fittings. System integrity was confirmed before each sorption measurement by a helium leak test at 69 bar. The effect of leakage was further minimized by utilizing desorption rather than adsorption experiments, thus allowing pressure measurements to be made at the low pressures obtained after expansion into the desorption reservoir. Leakage across valves was minimized by compartmentalization in the apparatus design by adding "pressure locks". Secondly, ideal gas law corrections were confirmed via hydrogen desorption experiments with inactive samples. Similar to the results discussed by

Table 4. Hydrogen Adsorption at High Pressure

\begin{tabular}{|c|c|c|c|c|}
\hline Name & Pretreatment & $T$, Ads. & $\begin{array}{l}\text { Total Hydrogen } \\
\text { Desorption } \\
(\text { wt. } \%)\end{array}$ & $\begin{array}{c}\text { Calculated } \\
\mathrm{H}_{\mathrm{x}} \mathrm{Ni}_{0.4} \mathrm{Mg}_{0.6} \mathrm{O}, \\
\mathrm{x}=\end{array}$ \\
\hline \multicolumn{5}{|c|}{ NIMgO Sample, Text $=510$} \\
\hline NIMGO-a1 & $\mathrm{H}_{2}-430^{\circ} \mathrm{C}($ external $)$ & 62 & $1.36 \%$ & 0.73 \\
\hline NIMGO-a2 & $\mathrm{H}_{2}^{2}-430^{\circ} \mathrm{C}($ external $)$ & 95 & $1.26 \%$ & 0.68 \\
\hline NIMGO-a3 & $\mathrm{H}_{2}^{2}-430^{\circ} \mathrm{C}($ external $)$ & 122 & $1.31 \%$ & 0.71 \\
\hline \multicolumn{5}{|c|}{ High Temperature in situ $M W$ formation } \\
\hline \multicolumn{5}{|c|}{ Mwin-NiMgO Sample $\left(\mathrm{T}\right.$ in $\left.=650^{\circ} \mathrm{C}, 20 \mathrm{~min} \mathrm{CH}_{4}\right)$} \\
\hline Mwin650-b1 & $\mathrm{H}_{2}-650^{\circ} \mathrm{C}($ external $)$ & 62 & $1.52 \%$ & 0.82 \\
\hline Mwin650-b2 & $\mathrm{H}_{2}-650^{\circ} \mathrm{C}($ external $)$ & 95 & $1.79 \%$ & 0.97 \\
\hline Mwin650-b3 & $\mathrm{H}_{2}^{2}-650^{\circ} \mathrm{C}($ external $)$ & 122 & $1.08 \%$ & 0.58 \\
\hline \multicolumn{5}{|c|}{ Additional $\mathrm{CH}_{4}$ treatment, +2 hour at $650^{\circ} \mathrm{C}$} \\
\hline Mwin650-b4 & $\mathrm{H}_{2}-650^{\circ} \mathrm{C}($ external $)$ & 62 & $1.08 \%$ & 0.58 \\
\hline Mwin650-2-b5 & $\mathrm{H}_{2}^{2}-650^{\circ} \mathrm{C}($ external $)$ & 95 & $1.79 \%$ & 0.97 \\
\hline Mwin650-2-b6 & $\mathrm{H}_{2}^{2}-650^{\circ} \mathrm{C}($ external $)$ & 122 & $1.23 \%$ & 0.66 \\
\hline \multicolumn{5}{|c|}{ Variation of Pretreatment Temp. for $\mathrm{MW} / \mathrm{NiMgO}$} \\
\hline Mw615-c1 & $\mathrm{He}-300^{\circ} \mathrm{C}($ internal $)$ & T-P cycle & $0.42 \%$ & NA \\
\hline Mw615-c2 & $\mathrm{H}_{2}-700^{\circ} \mathrm{C}$ (internal) & T-P cycle & $1.01 \%$ & NA \\
\hline Mw615-c3 & $\mathrm{H}_{2}-700^{\circ} \mathrm{C}($ external $)$ & T-P cycle & $0.88 \%$ & NA \\
\hline Mw615-c4 & $\mathrm{H}_{2}-800^{\circ} \mathrm{C}($ external $)$ & T-P cycle & $1.55 \%$ & NA \\
\hline Mw625-c5 & $+500^{\circ} \mathrm{C}($ internal $)$ & T-P cycle & $3.60 \%$ & NA \\
\hline
\end{tabular}

\footnotetext{
* The values for $\mathrm{x}$ are estimated from the desorption value and assume all hydrogen desorbs.
} 


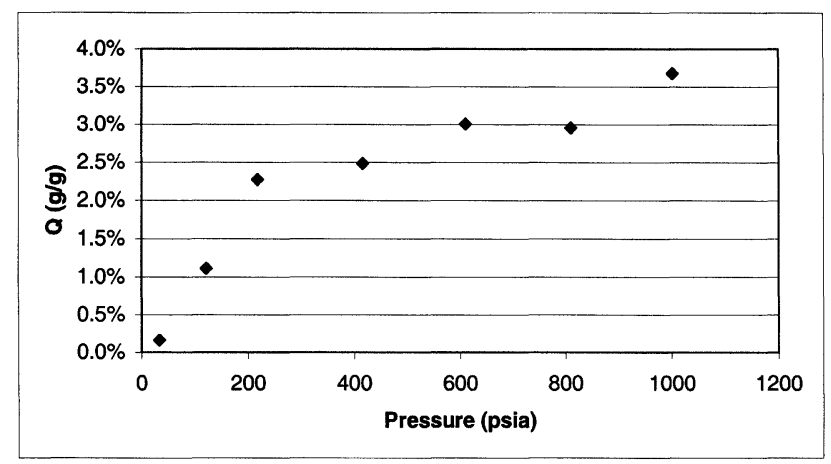

Figure 10. Adsorption isotherm of final $\mathrm{MW} / \mathrm{NiMgO}$ system after external pretreatment in $800^{\circ} \mathrm{C}$ $\mathrm{H}_{2}$ followed by $500^{\circ} \mathrm{C}$ vacuum in the adsorption apparatus.

The corresponding value of desorption showed a maximum value of $3.6 \%$. (Note: 1,000 psia $=69$ bar).

Tibbets et al. (2001), temperature variations were observed upon gas expansion into an empty reservoir - for both hydrogen and helium, with and without the sample present. In our system, this effect was most pronounced for expansion from high pressures into a vacuum, and generally depended upon the pressure difference. To compensate for this effect, each hydrogen expansion measurement has been corrected based on corresponding blank helium measurements.

High-Pressure Adsorption and Desorption Studies. The maximum hydrogen desorption from the $\mathrm{MW} / \mathrm{NiMgO}$ system was $3.6 \%$; this value was obtained after an $800^{\circ} \mathrm{C}$ external hydrogen treatment followed by a $500^{\circ} \mathrm{C}$ vacuum internal pretreatment followed by adsorption using the T-P cycle(Table 4c). The T-P cycle was conducted with flowing hydrogen and was designed to approximate the temperature profile found in the TGA cycles, while incrementally increasing the pressure to 69 bar. A separate batch adsorption isotherm experiment showed a maximum adsorption of $3.7 \%$ at 69 bar (Figure 10). Comparison of the adsorption measured at ambient pressure in the high-pressure system $(\sim 0.17 \%$, Figure $10)$ to that reported with TGA measures $(0.68 \%$, Figure 3$)$ shows a slight inconsistency; however, the difference may be due to a number of effects, including: sample differences, hydrogen exposure techniques, and/or equipment differences. The measurement error of the pressure transducer in the high-pressure system is 1 psi, making ambient pressure measurements particularly problematic. In any case, the highpressure measurements are of more relevance since they more closely approach the DOE targets. The agreement between the flowing desorption experiment and the batch adsorption measure at 69 bar rules out water contamination, as the effect of water contamination during a batch experiment will be minimal.

The shape of the adsorption isotherm suggests that the sample is not yet saturated at 69 bar and that there is a potential to increase the uptake at higher pressures. Comparing the results presented here to previous reports is not necessarily straightforward, as previous studies have generally been at higher pressures and have not included adsorption isotherms. At ambient temperatures, SWNT have been reported to store $4 \%$ at 120 bar (Liu et al., 1999), while MWNT reports at ambient temperatures range from $1.97 \%$ at 40 bar (Lee et al., 2002) to $4 \%$ at 100 bar (Li et al., 2001) to $6.3 \%$ at 148 bar (Hou et al., 2002). Although none of these studies have considered the effect of residual metals, an unsaturated hydrogen uptake of $3.6 \%$ at 69 bar is certainly promising and can be further optimized by understanding the hydrogen spillover process from the $\mathrm{H}_{\mathrm{x}} \mathrm{Ni}_{\mathrm{y}} \mathrm{Mg}_{1-\mathrm{y}} \mathrm{O}$ to the nanotube surface. As discussed previously, the hydrogen spillover is certainly a function of the carbon-catalyst contact, and this can be optimized via high-temperature pretreatment. Furthermore, the hydrogen spillover effect can be optimized by increasing the surface area of the catalyst, trying different catalyst-carbon combinations, and further optimizing catalyst-support interactions.

Understanding and Optimizing Hydrogen Spillover. Insight into the optimization of hydrogen spillover can be gained through analysis of the results by which a 3.6\% desorption value was obtained. A series of experiments were performed, including: (a) characterization of the $\mathrm{NiMgO}$ catalyst at high pressures; (b) an attempt to optimize in situ formation of MWNT and subsequent high-pressure results; and (c) variation of pretreatment temperature.

Characterization of the $\mathrm{NiMgO}$ catalyst after activation at $400^{\circ} \mathrm{C}$ showed that desorption from the $\mathrm{NiMgO}$ catalyst was consistently $1.3 \%$ after 69 bar adsorption at all three adsorption temperatures (Table 4a). The consistency of these three values confirms the precision of the experimental procedure, but suggests that the adsorption temperature may be an insignificant factor-either due to the subsequent cooling or due to the lack of temperature effects at high pressure. Comparing the high-pressure $\mathrm{H}: \mathrm{Me}$ ratio of 0.7 to the $0.3 \mathrm{H}: \mathrm{Me}$ ratio found at low pressure shows that the high pressure substantially increased the saturation of the $\mathrm{Ni}_{0.4} \mathrm{Mg}_{0.6} \mathrm{O}$ catalyst. This is consistent with reports that hydrogen intercalation in metal oxides increases with increasing pressure (Fripiat and Lin, 1992).

Optimization of the carbon to metal contact via in situ formation of MWNT resulted in a slight increase in uptake compared to the $\mathrm{Ni}_{0.4} \mathrm{Mg}_{0.6} \mathrm{O}$ (Table 4b). This enhancement was most pronounced at an adsorption temperature of $95^{\circ} \mathrm{C}$. The H:Me ratio was increased from 0.7 to 0.97 after the in situ nanotube formation, suggesting hydrogen spillover. Subsequent hydrogen adsorption measurements at $62^{\circ} \mathrm{C}$ and $122^{\circ} \mathrm{C}$ resulted in a decreased desorption amount; however, it is not clear if this is due to temperature or cycling effects. These studies show that an increase in hydrogen uptake and subsequent desorption is possible with in situ nanotube formation; however, the adsorption may be reduced with subsequent exposures. The relative lack of control of the synthesis conditions limits the applicability of this method to optimize the hydrogen storage of the system.

Increasing pretreatment temperature resulted in increased high-pressure adsorption, resulting in a maximum desorption value of $3.6 \%$, as mentioned above (Table 4c). A background reading of $0.42 \%$ was obtained for hydrogen desorption after treatment at $300^{\circ} \mathrm{C}$ in flowing helium. Pretreatment of the sample in $700^{\circ} \mathrm{C}$ hydrogen increased the amount to $1.01 \%$, whereas a small increase to $1.55 \%$ was realized by pretreatment at $800^{\circ} \mathrm{C}$. The maximum desorption value was obtained when the external pretreatment was followed by an additional $500^{\circ} \mathrm{C}$ vacuum pretreatment, suggesting possible oxy- 
gen exposure when the sample transfer contaminates and/or partially deactivates the sample. Further evidence of detrimental oxygen effects was found with a final desorption series, which resulted in particularly low hydrogen desorption values when compared to the other results (data not shown).

Experiments are underway to examine the reproducibility of the adsorption, although a comparison of a $3.6 \%$ desorption value to a subsequent $3.7 \%$ adsorption uptake on the same sample is certainly promising. Experiments designed to optimize hydrogen spillover and to understand the effects of oxygen exposure, nanotube synthesis conditions, and catalyst content are also underway.

\section{Summary and Conclusions}

(1) Hydrogen uptake in the MWNT is due to spillover from a $\mathrm{NiMgO}$ catalyst.

(2) The bulk of the NiMgO catalyst remains in oxidized form, although surface Ni may become reduced. Activated $\mathrm{MgO}$ is capable of dissociating and storing hydrogen. Hydrogen becomes absorbed into the bulk of the $\mathrm{NiMgO}$ leading to the formation of $\mathrm{H}_{\mathrm{x}} \mathrm{Ni}_{\mathrm{y}} \mathrm{Mg}_{1-\mathrm{y}} \mathrm{O}$.

(3) The following mechanism can be deduced: the hydrogen chemisorbs to surface sites found on the NiMgO. Bridges between the catalyst and carbon allow the chemisorbed hydrogen to migrate onto the carbon surface. Desorption occurs directly from the relatively lower energy carbon sites without migration back to the catalyst.

(4) Hydrogen spillover depends upon the carbon-catalyst contact. The contact changes with the quality of the MWNT as determined by its yield and its pretreatment temperature.

(5) Increasing the pretreatment temperature from $500^{\circ} \mathrm{C}$ to $700^{\circ} \mathrm{C}$ activates the MWNT based on normalized and absolute hydrogen uptake. The increase in pretreatment temperature likely enhances the metal-catalyst contact. In addition, uptake measurement on doped GNF combined with temperature activation studies indicate that higher pretreatment temperatures may create catalytic sites on the $\mathrm{MgO}$ leading to increased hydrogen storage.

(6) Rigorous high-pressure hydrogen experiments resulted in adsorption and desorption from the $\mathrm{MW} / \mathrm{NiMgO}$ system of $3.7 \%$ and $3.6 \%$, respectively. The adsorption isotherm suggests that the system is not yet saturated at 69 bar. To increase the uptake above a base line value of $0.4 \%$, pretreatment temperatures of $800^{\circ} \mathrm{C}$, followed by additional $500^{\circ} \mathrm{C}$ vacuum pretreatment were necessary. Oxygen exposure during transfer lowered high-pressure hydrogen uptake.

\section{Acknowledgments}

The authors would like to thank Leah Minc of the Michigan Memorial Phoenix Project for conducting the elemental analysis on the Ford Nuclear Reactor. This work was funded by NSF CTS0138190 .

\section{Literature Cited}

AIChE Meeting, "Chemical Engineering Issues in Carbon Nanotubes," Sessions 1 and 4, Indianapolis, IN (Nov. 2002).

Bockrath, B.C., M. Smith, and E. Bittner, "Activating Single-walled Carbon Nanotubes for Gas Storage," AIChE Meeting, Paper 1h, Indianapolis, IN (Nov. 2002).

Boudart, M., A. W. Aldag, and M. A. Vannice, "On the Slow Uptake of Hydrogen by Platinized Carbon,” J. Catal., 18, 46 (1970).
Browning, D. J., M. L. Gerrard, J. B. Lakeman, I. M. Mellor, R. J. Mortimer, and M. C. Turpin, "Studies into the Storage of Hydrogen in Carbon Nanofibers: Proposal of a Possible Reaction Mechanism," Nano Lett., 2, 201 (2002).

Cassell, A. M., J. A. Raymakers, J. Kong, and H. Dai, "Large Scale CVD Synthesis of Single-Walled Carbon Nanotubes," J. Phys. Chem. B., 103, 6464 (1999).

Chen, P., X. Wu, J. Lin, and K. L. Tan, "High $\mathrm{H}_{2}$ Uptake by AlkaliDoped Carbon Nanotubes Under Ambient Pressure and Moderate Temperatures," Science, 285, 91 (1999).

Chen, P., H.-B. Zhang, G.-D. Lin, Q. Hong, and K. R. Tsai, "Growth of Carbon Nanotubes by Catalytic Decomposition of $\mathrm{CH}_{4}$ or $\mathrm{CO}$ on a Ni-MgO Catalyst," Carbon, 35, 1495 (1997).

Cheng, H.-M., Q.-H. Yang, and C. Liu, "Hydrogen Storage in Carbon Nanotubes," Carbon, 39, 1447 (2001).

Darkrim, F. L., P. Malbrunot, and G. P. Tartaglia, "Review of Hydrogen Storage by Adsorption in Carbon Nanotubes," Int. J. Hydrogen Energ., 27, 193 (2002).

Darkrim, F., J. Vermesse, P. Malbrunot, and D. Levesque, "Monte Carlo Simulations of Nitrogen and Hydrogen Physisorption at High Pressures and Room Temperature. Comparison with Experiments," J. Chem. Phys., 110, 4020 (1999).

Delahaye, A., A. Aoufi, A. Gicquel, and I. Pentchem, "Improvement of Hydrogen Storage by Adsorption Using 2-D Modeling of Heat Effects," AIChE J., 48, 2061 (2002).

Dillon, A. C., K. M. Jones, T. A. Bekkedahl, C. H. Kiang, and D. S. Bethune, "Storage of Hydrogen in Single-Walled Carbon Nanotubes," Nature, 386, 377 (1997).

Ding, R. G., G. Q. Lu, Z. F. Yan, and M. A. Wilson, "Recent Advances in the Preparation and Utilization of Carbon Nanotubes for Hydrogen Storage," J. Nanosci. Nanotech., 1, 7 (2001).

Erre, R., M. H. Legay, and J. J. Fripiat, "Reaction of Molecular Hydrogen with the 100 Face of $\mathrm{MoO}_{3}$ II," Surf. Sci., 127, 69 (1983).

Fripiat, J. J., and X. Lin, "Hydrogen Intercalation within Transition Metal Oxides: Entropy, Enthalpy, and Charge Transfer," J. Phys. Chem., 96, 1437 (1992).

Gadre, S. A., A. D. Ebner, S. A. Al-Muhtaseb, C. E. Holland, and J. A. Ritter, "Practical Modeling of Metal Hydride Hydrogen Storage Systems," AIChE Meeting, Paper 118f, Indianapolis, IN (Nov. 2002).

Goethel, P. J., and R. T. Yang, "Mechanism of Graphite Hydrogenation Catalyzed by Nickel," J. Catal., 108, 356 (1987).

Heung, L. K., T. Motyka, and W. A. Summers, "Hydrogen Storage Development for Utility Vehicles," AIChE Meeting, Paper 70h, Indianapolis, IN (Nov. 2002).

Hirscher, M., M. Becher, M. Haluska, U. Dettlaff-Weglikowska, A. Quintel, G. S. Duesberg, Y.-M. Choi, P. Downes, M. Hulman, S. Roth, I. Stepanek, and P. Bernier, "Hydrogen Storage in Sonicated Carbon Materials," Appl. Phys. A, 72, 129 (2001).

Hou, P.-X., Q.-H. Yang, S. Bai, S.-T. Xu, M. Liu, and H.-M. Cheng, "Bulk Storage Capacity of Hydrogen in Purified Multiwalled Carbon Nanotubes," J. Phys. Chem. B, 106, 963 (2002).

Ito, T., M. Kuramoto, M. Yoshioka, and T. Tokuda, "Active Sites for Hydrogen Adsorption on Magnesium Oxide," J. Phys. Chem., 87, 4411 (1983).

Ito, T., T. Murakami, and T. Tokuda, "Hydrogen Adsorption on Magnesium Oxide Powders," J. Chem. Soc., Faraday Trans. 1, 77, 2181 (1981).

Kiselev, V. F., and O. V. Krylov, Adsorption and Catalysis on Transition Metals and their Oxides, Springer-Verlag, New York, pp. 51-53 (1989).

Krishnakutty, N., C. Park, N. M. Rodriguez, and R. T. K. Baker, "The Effect of Copper on the Structural Characteristics of Carbon Filaments Produced from Iron Catalyzed Decomposition of Ethylene," Catalysis Today, 37, 295 (1997).

Kuznetsova, A., J. R. Yates, Jr., J. Liu, and R. E. Smalley, "Physical Adsorption of Xenon in Open Single Walled Carbon Nanotubes: Observation of a Quai-One-Dimensional Confined Xe Phase," J. Chem. Phys., 112, 9590 (2000).

Lamari, M., A. Aoufi, and P. Malbrunot, "Thermal Effects in Dynamic Storage of Hydrogen by Adsorption," AIChE J., 46, 632 (2000).

Lee, H., Y.-S. Kang, S.-H. Kim, and J.-Y. Lee, "Hydrogen Desorption Properties of Multiwall Carbon Nanotubes with Closed and Open Structures," Appl. Phys. Lett., 80, 577 (2002). 
Li, X., H. Zhu, L. Ci, C. Xu, Z. Mao, B. Wei, J. Liang, and D. Wu, "Hydrogen Uptake by Graphitized Multiwalled Carbon Nanotubes Under Moderate Pressure at Room Temperature," Carbon, 39, 2077 (2001).

Liu, C., Y. Y. Fan, M. Liu, H. T. Cong, H. M. Cheng, and M. S. Dresselhaus, "Hydrogen Storage in Single-Walled Carbon Nanotubes at Room Temperature," Science, 286, 1127 (1999).

Lueking, A., and R. T. Yang, "Hydrogen Spillover from a Metal Oxide Catalyst onto Carbon Nanotubers - Implications for Hydrogen Storage," J. Catal., 206, 165 (2002).

Lueking, A., and R. T. Yang, Unpublished data (2003).

Lunsford, J. H., and J. P. Jayne, "An Electron Paramagnetic Resonance Study of Surface Defects on Magnesium Oxide," J. Phys. Chem., 70, 3464 (1966).

Marcq, J. P., X. Wispenninckx, G. Poncelet, D. Keravis, and J. J. Fripiat, "Hydrogenation by Hydrogen Bronzes," J. Cat., 73, 309 (1982).

Paganini, M. C., M. Chiesa, E. Giamello, S. Coluccia, G. Martra, D. M. Murphy, and G. Pacchioni, "Colour Centers at the Surface of Alkali-Earth Oxides. A New Hypothesis on the Location of Surface Electron Traps," Surf. Sci., 421, 246 (1999).

Park, C., P. E. Anderson, A. Chambers, C. D. Tan, R. Hidalgo, and N. M. Rodriguez, "Further Studies of the Interaction of Hydrogen with Graphite Nanofibers," J. Phys. Chem. B, 103, 10572 (1999).

Pichat, P., M.-N. Mozzanega, and C. Van Hoang, "Room Temperature Photoassisted Formation of Hydrogen-Molybdenum Bronzes with an Alcohol as a Hydrogen Source," J. Phys. Chem., 92, 467 (1988).

Pinkerton, F. E., B. G. Wicke, C. H. Olk, G. G. Tibbetts, G. P. Meisner, M. S. Meyer, and J. F. Herbst, "Thermogravimetric Measure- ment of Hydrogen Absorption in Alkali-Modified Carbon Materials," J. Phys. Chem. B, 104, 9460 (2000).

Ritter, J. A., J. Gaillard, A. M. Rao, A. D. Ebner, and R. Zidan, "Adsorption of $\mathrm{H}_{2}$ on Pd and Ti Doped Multiwalled Carbon Nanotubes," AIChE Meeting, Paper 349c, Indianapolis, IN (Nov. 2002).

Sermon, P. A., and G. C. Bond, "Studies of Hydrogen Spillover," J.C.S. Faraday I, 76, 889 (1980).

Smith, D. R., and A. J. Tench, "Reaction of Hydrogen Atoms at Oxide Surfaces," Chem. Communications, 18, 1113 (1968).

Tench, A. J., and T. Lawson, "The Formation of O- and O3- Adsorbed on an Oxide Surface," Chem. Phys. Lett., 7, 459 (1970).

Tibbetts, G. G., G. P. Meisner, and C. H. Olk, "Hydrogen Storage Capacity of Carbon Nanotubes, Filaments, and Vapor-Grown Fibers," Carbon, 39, 2291 (2001).

Tinet, D., M. H. Legay, L. Gatineau, and J. J. Fripiat, "Properties of the Vanadium Pentoxide Hydrogen Bronzes $\left(\mathrm{H}_{2 \mathrm{x}} \mathrm{V}_{2} \mathrm{O}_{5}\right)$," J. Phys. Chem., 90, 948 (1986).

Yang, F. H., and R. T. Yang, "Ab initio Molecular Orbital Study of Adsorption of Atomic Hydrogen on Graphite: Insight into Hydrogen Storage in Carbon Nanotubes," Carbon, 40, 437 (2002).

Yang, R. T., "Hydrogen Storage by Alkali-Doped Carbon Nanotubes -Revisited," Carbon, 38, 623 (2000).

Yu, R., L. Chen, Q. Liu, J. Lin, K.-L. Tan, S. C. Ng, H. S. O. Chan, G.-Q. Xu, and T. S. A. Hor, "Platinum Deposition on Carbon Nanotubes via Chemical Modification," Chem. Mater., 10, 718 (1998)

Manuscript received July 1, 2002, revision received Dec. 23, 2002, and final revision Feb. 18, 2003. 